\title{
Tourism Development Strategy in Pasuruan Regency
}

\section{Strategi Pengembangan Pariwisata di Kabupaten Pasuruan}

\author{
Hana Farasastin*, Ilmi Usrotin Choiriyah \\ Universitas Muhammadiyah Sidoarjo
}

Regional development is an integral part of national development in accordance with the mandate of Law number 33 of 2004 concerning financial balance between the central government and regional governments where regions can manage their own households to accelerate the realization of community welfare. Therefore, the Regional Government is given the authority to explore its own sources of income. PAD consists of the results of regional taxes, the results of regional levies, the results of separated regional wealth management and other legitimate regional income. In Pasuruan Regency the tourism sector has not become a major contributor to PAD so that in order to achieve this goal the Pasuruan Regency Culture and Tourism Office requires a tourism development strategy. The purpose of this study is to analyze and describe tourism development strategies by the Pasuruan Regency Culture and Tourism Agency in increasing PAD. The method used is a qualitative method with data collection carried out by means of observation, interviews and documentation. The results of this study state that there are several types of strategies namely Corporate Strategy, Strategy Program, Resources Support Strategy and Institutional Strategy in tourism development carried out by the Culture Service and Pasuruan Regency Tourism in increasing PAD in Pasuruan Regency. Of the four types of strategies in Pasuruan Regency the most prominent strategies are Corporate Strategy and Strategy Program.

ISSN 2527-9246 (online) ISSN 2338-445X (print)

Edited by:

Sri Juni Woro Astuti

Reviewed by:

Bambang Kusbandrijo and Gede

Sandiasa

*Correspondence:

Hana Farasastin

hanafarasastin@umsida.ac.id

Published: 1 Maret 2020

Citation:

Farasastin H and Choiriyah IU (2020) Tourism Development

Strategy in Pasuruan Regency.

JKMP (Jurnal Kebijakan dan

Manajemen Publik). 8:1.

doi: $10.21070 / j k m p . v 8 i 1.758$
Keywords: Strategy, Tourism Development, PAD

\section{PENDAHULUAN}

Dalam rangka memajukan pembangunan perekonomian untuk kesejahteraan masyarakat, maka pemerintah menetapkan daerah yang berpotensi sebagai tujuan wisata. Kondisi dan iklim Pariwisata mempunyai peranan yang sangat urgen sebagai roda penggerak pengembangan serta pembangunan sebuah daerah. pariwisata pada era saat ini telah menjadi sebuah industri yang menjadi tujuan sebagian besar masyarakat lokal maupun mancanegara. Kabupaten Pasuruan sebagai daerah yang memiliki keberagaman kindahan alam, seni maupun budaya sehingga Kabupaten Pasuruan menjadikan pariwisata sebagai penunjang PAD. Dengan keberagaman budaya yang ada, diperlukan pengelolaan yang tepat sehingga potensi tersebut dapat dikelola dengan baik dan mendapatkan manfaat yang besar untuk masyarakat daerah. Strategi Pengembangan pariwisata pada observasi awal, peneliti mendapatkan konsepsi sebuah obyek strategi yang selama ini diimplementasikan oleh Dinas Kebudayaan dan Pariwisata Kabupaten 
Pasuruan yakni pembangunan berwawasan lingkungan dimana pembangunan berwawasan lingkungan ini berhubungan langsung dengan pembangunan ekonomi lokal sehingga akan meningkatkan sebuah keraifan lokal yaitu kekayaan yang dimiliki oleh daerah. Namum pada kenyataannya sektor pariwisata belum menjadi penunjang utama Pendapatan Asli Daerah Kabupaten Pasuruan dapat kita lihat dari tebel mengenai Pendapatan Asli Daerah sektor pariwisata Kabupaten Pasuruan seperti dibawah ini.

TABLE 1 | PAD Sektor Pariwisata Kabupaten Pasuruan Tahun 2013-2017

\begin{tabular}{ll}
\hline Tahun & PAD Sektor Pariwisata \\
2013 & $19.336 .635 .976,47$ \\
2014 & $22.355 .180 .518,00$ \\
2015 & $27.114 .820 .546,42$ \\
2016 & $32.012 .035 .836,59$ \\
2017 & $36.913 .053 .245,58$ \\
\hline
\end{tabular}

Dari data diatas dapat kita lihat bahwa setiap tahunnya PAD sektor pariwisata selalu meningkat. Dengan adanya hal tersebut diharapkan sektor pariwisata menjadi penyumbang PAD Kabupaten Pasuruan yang cukup besar melihat sektor pariwisata Kabupaten Pasuruan sangat potensial dengan keberagaman pariwisata yang dimiliki di Kabupaten Pasuruan. Namun, secara umum banyak lokasi wisata yang masih belum dikelola sendiri oleh pemerintah dengan baik. Hanya tiga lokasi wisata saja yang keseluruhannya dikelola oleh pemerintah khususnya Kabupaten Pasuruan yaitu Ranu Grati, Pemandian Alam Banyu Biru dan Gunung Bromo. Dapat kita bayangkan jika lebih dari 3 lokasi pariwisata yang pemerintah kelola sendiri maka dimungkinkan PAD dari sektor pariwisata dan juga memiliki 43 lokasi wisata yang terdiri dari lokasi wisata alam, seni budaya dan religi. Kabupaten Pasuruan akan terus mengalami peningkatan jika dilakukan dengan beberapa jenis startegi.

Strategi

Strategi merupakan sebuah goal akhir yang diimplementasikan dalam waktu jangka yang panjang, kegiatan tindak lanjut dalam hal ini sebuah prioritas sumber daya penekanannya yakni terbuka peluang untuk mengidentifikasi dalil-dalil yang memungkinkan kategorisasi penerapan strategi organisasi publik ke dalam empat corak persilangan. Terkait dalam ciri-ciri spesifik dari keempat jenis strategi publik, yaitu corporate strategy (strategi organisasi), program strategy (strategi program), resources support strategy (strategi pendukung sumber daya) dan institusional strategy (strategi kelembagaan) (Salusu, 2006).

\section{Pendapatan Asli Daerah}

Pendapatan asli daerah (PAD) merupakan penerimaan yang diperoleh daerah dari sumbersumber dalam wilayahnya sendiri yang dipungut berdasarkan peraturan daerah sesuai dengan peraturan perundang-undangan yang berlaku dengan tujuan untuk memberikan keleluasaan kepada daerah dalam menggali pendaan dalam pelaksanaan otonomi daerah sebagai perwujudan asas desentralisasi. Menurut Undang-Undang No 33 Tahun 2004 PAD sendiri bersumber dari antara lain: Pajak Daerah, Retribusi Daerah, hasil pengelolaan kekayaan Daerah yang dipisahkan, dan lain-lain PAD yang sah. Halim (2007) .

\section{METODE PENELITIAN}

Metode penelitian ini menggunakan jenis penelitian deskriptif dengan pendekatan kualitatif Sugiyono (2015) . Hal ini dilakukan dengan cara menggali data terkait strategi kolaborasi dalam meningkatkan PAD Kabupaten Pasuruan dengan pendekatan kualitatif melalui observasi, wawancara dan dokumentasi. Teknik penentuan informan dilakukan secara snowball sampling Nawawi (2007). Dalam pengumpulan data menggunakan wawancara dengan beberapa informan kunci dalam penelitian ini yakni Sekretaris dinas di Dinas Kebudayaan dan Pariwisata Kabupaten Pasuruan. Hal ini dikarenakan data-data yang terkait dengan pelaksanaan strategi pengembangan pariwisata di Kabupaten Pasuruan yang dibutuhkan dalam penelitian ini hanya bisa didapat dari informan kunci tersebut. Teknik penganalisisan data dalam penelitian ini menggunakan teknik menurut Miles dan Hubberman yaitu pengumpulan data, reduksi 
data, penyajian data dan penarikan kesimpulan Miles and Huberman (1992) .

\section{HASIL DAN PEMBAHASAN}

\section{Strategi Pengembangan Pariwisata Di Kabupaten Pasuruan}

Masyarakat membutuhkan lokasi wisata untuk dikunjungi. Di Kabupaten Pasuruan memiliki potensi pariwisata yang cukup potensial terdiri dari pariwisata alam, seni budaya, agama dan lain sebagainya. Dengan adanya kondisi pariwisata yang sedemikian maka diharapkan Kabupaten Pasuruan merupakan salah satu destinasi wisata yang dipilih oleh masyarakat sekitar maupun mancanegara untuk dikunjungi. Namun, tidak cukup hanya keberagaman lokasi wisata saja yang dapat menjadikan Kabupaten Pasuruan menjadi destinasi wisata yang dipilih oleh masyarakat tetapi Kabupaten Pasuruan juga harus terus memiliki startegi pengembangan pariwisata guna mencapai tujuan tersebut. Banyaknya wisatawan yang berkunjung ke Kabupaten Pasuruan dapat mempengaruhi jumlah pendapatan asli daerah Kabupaten Pasuruan dari sektor pariwisata. Dibawah ini merupakan startegi pengembangan pariwisata yang telah dilakukan oleh Pemerintah Kabupaten Pasuruan khususnya Dinas Kebudayaan dan Pariwisata Kabupaten Pasuruan sebagai berikut:

\section{Corporate strategy (strategi organisasi)}

Corporate Strategy (strategi organisasi) merupakan suatu strategi yang berkaitan dengan misi, tujuan dan nilai-nilai yang diperlukan guna mengetahui apa dan untuk siapa strategi tersebut dilakukan Wahab (2003) . Dalam hal tersebut startegi yang dilakukan oleh Dinas Kebudayaan dan Pariwisata Kabupaten Pasuruan telah sesuai dengan misi, tujuan dan nilai-nilai sebagaimana yang diutarakan oleh Bapak Djoko Pudjo selaku Sekretaris pada Dinas Kebudayaan dan Pariwisata Kabupaten Pasuruan sebagai berikut:

"Ada beberapa program startegi (corporate startegy) yang dilakukan oleh Dinas yaitu strategi pengembangan pariwisata, strategi pengelolaan kekayaan budaya, strategi pengembangan destinasi wisata, strateggi pengelolaan keragaman budaya serta startegi pengembangan kemitraan. Semua strategi tersebut sudah kita sesuaikan dengan misi, tujuan dan nilai yang kita miliki mbak." (Wawancara, tanggal 10 Januari 2019)

Pernyataan diatas wawancara diatas secara sepesifik mengungkapkan bahwa strategi organisasi yang telah dilakukan oleh Dinas Kebudayaan dan Pariwisata Kabupaten Pasuruan meliputi strategi pengembangan dan pemasaran pariwisata, strategi pengelolaan keberagaman budaya, strategi pengembangan destinasi wisata, strategi pengembangan kemitraan merupakan beberapa startegi organisasi yang dilakukan oleh Dinas Kebudayaan dan Pariwisata Kabupaten Pasuruan yang dinilai sudah sesuai dengan visi, misi dan tujuan serta nilai-nilai. Salah satu kegiatan yang dilakukan yaitu dengan melakukan kolaborasi dengan Dinas Koperasi dan UMKM Kabupaten Pasuruan guna membentuk UMKM pariwisata.

\section{Strategy Progr am (program strategi)}

Strategy Program (program strategi) merupakan strategi yang memberi perhatiannya kepada dampak suatu program jika suatu program tersebut diberikan dan dilaksanakan Sunaryo (2013) . Dinas Kebudayaan dan Pariwisata Kabupaten Pasuruan adalah Dinas yang memiliki wewenang dalam mengembangkan pariwisata Kabupaten Pasuruan yang lebih menekankan kepada program yang disesuaikan dengan tugas pokok dan fungsi Dinas sebagaimana disampaikan oleh Bapak Djoko Pudjo selaku Sekretaris pada Dinas Kebudayaan dan Pariwisata Kabupaten Pasuruan sebagai berikut:

"Sesuai tugas pokok dan fungsi kita sebagai pelayan masyarakat dalam melakukan atau membuat suatu program tentunya diseusikan sama visi misi kita mbak. ada beberapa program yang kita jalankan setiap tahunnya salah satunya Bromo Marathon, festival durian kakap, gelar seni Candi Jawi dan hari jadi Kabupaten Pasuruan itu semua memberikan dampak baik mbak." (Wawancara, tanggal 10 Januari 2019)

Pernyataan diatas memperkuat bahwa program strategi yang dilakukan oleh Dinas Kebu- 
dayaan dan Pariwisata Kabupaten Pasuruan antara lain Bromo Marathon, festival durian kakap, gelar seni candi jawi dan hari jadi Kabupaten Pasuruan sejauh ini memiliki dampak positif bagi perkembangan ekonomi masyarakat dan peningkatan PAD Kabupaten Pasuruan melalui sektor pariwisata. Dampak yang ditimbulkan yaitu meningkatnya jumlah wisatawan yang berkunjung ke Kabupaten Pasuruan khususnya pada lokasi even.

\section{Resources Support S trategy (strategi pendukung sumber daya)}

Resources support strategy (startegi pendukung sumber daya) merupakan strategi yang memaksimalkan sumber daya yang dimiliki untuk meningkatkan kinerja organisasi Yoeti (2008) . seperti yang disampaikan oleh Bapak Djoko Pudjo selaku Sekretaris pada Dinas Kebudayaan dan Pariwisata Kabupaten Pasuruan sebagai berikut:

"Sumber daya yang kita miliki selalu kita kelola semaksimal mungkin mbak. Dengan begitu harapannya kita dapat memberikan pelayanan yang baik dan tujuan kita tercapai. Untuk memaksimalkan kemampuan ASN kita dengan melakukan diklat dan studi banding. Kalau mengenai dana jelas kita kelola dengan baik yaitu dengan membuat even mbak. sedangkan sumber daya alam kita manfaatkan dengan baik sebagai

lokasi wisata namun kita tetap menjadi kelestariannya." (Wawancara, tanggal 10 Januari 2019)

Pernyataan diatas dapat ditarik sebuah pemahaman bahwa strategi pendukung sumber daya yang dilakukan oleh Dinas Kebudayaan dan Pariwisata Kabupaten Pasuruan yaitu memanfaatkan sumber daya pendukung berupa sumber daya manusia. Dinas Kebudayaan dan Pariwisata Kabupaten Pasuruan melakukan peningkatkan kemampuan ASN dengan melakukan diklat dan studi banding guna memberikan pengetahuan baru dan dapat menciptakan inovasi yang baru untuk mencapai tujuan yang diinginkan. Sedangkan dalam memanfaatkan sumber daya pendukung berupa keuangan, Dinas Kebudayaan dan Pariwisata membuat eveneven guna menambah ketertarikan masyarakat untuk berkunjung ke Kabupaten Pasuruan serta membangun sarana dan prasarana pendukung dalam mengembangkan destinasi wisata. Serta dalam memanfaatkan sumber daya alam juga sangat dimaksimalkan dengan mengembangkan dan tetap menjaga kelestarian lingkungan sehingga tetap dapat dimanfaatkan dan dirasakan keuntungannya secara terus-menerus dan berimbas kepada PAD Kabupaten Pasuruan dengan cara melakukan pertunjukan berupa seni budaya sesuai dengan daerah wisata masing-masing.

\section{Institusional Strategy (startegi kelembagaan)}

Institusional strategy (strategi kelembagaan) berfokus pada pengembangan kemampuan organisasi untuk melaksanakan inisiatiff-inisiatif startegi baru. Dinas Kebudayaan dan Pariwisata Kabupaten Pasuruan telah melakukan institusional strategy (strategi kelembagaan) diperkuat dnegan pernyataan Bapak Djoko Pudjo selaku Sekretaris pada Dinas Kebudayaan dan Pariwisata Kabupaten Pasuruan sebagai berikut:

"Saya rasa kita sudah melakukan strategi kelembagaan itu dengan membuat inovasi baru yang kita lakukan bersama dengan dinas lain yang ada di Kabupaten pasuruan mbak. Salah satunya dengan inovasi SATRYA EMAS (pusat strategi dan pelayanan ekonomi maslahat)." (Wawancara, tanggal 10 Januari 2019)

Pernyataan diatas dapat memperkuat bahwa startegi kelembagaan Kabupaten Pasuruan dapat kita lihat dengan inovasi-inovasi yang tentunya dapat meningkatkan PAD Kabupaten Pasuruan melalui sektor pariwisata. Salah satunya inovasi berupa SATRYA EMAS dimana memiliki tujuan dalam memaksimalkan pr ogram layanan kewirausahaan yang mandiri, profesional dan maslahat yang tentunya memiliki pengaruh terhadap perekonomian masyarakat dan meningkatkan PAD Kabupaten Pasuruan.

\section{KESIMPULAN}

Pertama, Strategi dalam pengembangan pariwisata yang berlokasi di Kabupaten Pasuruan dalam meningkatkan PAD terdapat corporate Strategy (strategi organisasi) yang dilaksanakan 
secara sistematis oleh Dinas Kebudayaan dan Pariwisata Kabupaten Pasuruan dilakukan untuk mencapai kepariwisataan yaitu strategi pengembangan pemasaran pariwisata, strategi pengelolaan kekayaan budaya, strategi pengembangan destinasi pariwisata, strategi pengelolaan keragaman budaya serta program pengembangan kemitraan. Kedua, Strategi yang dilakukan oleh Dinas Kebudayaan dan Pariwisata Kabupaten Pasuruan diatas telah sesuai dengan visi, misi dan tujuan yang dimiliki oleh Kabupaten Pasuruan. Program strategy (strategi program) yang dilakukan oleh Dinas Kebudayaan dan Pariwisata Kabupaten Pasuruan yaitu diantaranya Bromo Marathon, festival durian kakap, gelar seni Candi Jawi dan hari jadi Kabupaten Pasuruan. Ketiga, Intitusional strategy (strategi kelembagaan) berfokus kepada pengembangan organisasi dalam pelaksanaan inisitif atau inovasi dalam strategi salah satunya dengan inovasi SATRYA EMAS (pusat strategi dan pelayanan ekonomi maslahat).

\section{UCAPAN TERIMA KASIH}

Penulis sangat berterima kasih kepada Civitas Akademika Universitas Muhammadiyah Sidoarjo, karena berkat dukungan yang sangat luar biasa artikel jurnal penelitian ini dapat terselesaikan dengan baik. Yang kedua, terima kasih kepada Pemerintah Kabupaten Pasuruan atas fasilitas yang diberikan penelii selama melakukan kegiatan survey dan observasi dilapangan. Ketiga, Penulis juga mengucapkan terima kasih atas perkenannya Jurnal Kebijakan dan Manajemen Publik (JKMP) Universitas Muhammadiyah Sidoarjo (UMSIDA) bisa mempublikasikan jurnal ini.

\section{REFERENCES}

Halim, A. (2007). Akutansi dan Pengendalian Keuangan DaerahSeri Bunga Rampai Manajemen Keuangan Daerah (Yogyakarta: UPP STIM YKPN).

Miles, B. and Huberman, A. M. (1992). Analisis Data Kualitatif (Jakarta: UI-Press).

Nawawi, H. (2007). Metode Penelitian Bidang Sosial (Yogyakarta: Gajah Mada University Press).

Salusu, J. (2006). Pengambilan Keputusan Strategik Untuk Organisasi Publik dan Organisasi Non Profit (Jakarta: Grasindo).

Sugiyono (2015). Metode Penelitian Kuantitatif Kualitatif dan $R \Leftarrow D$ (Bandung: Alfabeta).

Sunaryo, B. (2013). Kebijakan Pembangunan Destinasi Pariwisata Konsep dan Aplikasinya Di Indonesia, and others (ed.) (Yogyakarta: Gava media).

Wahab, S. (2003). Manajemen Kepariwisataan (Jakarta: PT. Pradnya Paramita).
Yoeti, O. A. (2008). Ekonomi Pariwisata: Introduksi, Informasi, dan Implementasi (Jakarta: Kompas).

Conflict of Interest Statement: The authors declare that the research was conducted in the absence of any commercial or financial relationships that could be construed as a potential conflict of interest.

Copyright (c) 2020 Farasastin and Choiriyah. This is an openaccess article distributed under the terms of the Creative Commons Attribution License (CC BY). The use, distribution or reproduction in other forums is permitted, provided the original author(s) and the copyright owner(s) are credited and that the original publication in this journal is cited, in accordance with accepted academic practice. No use, distribution or reproduction is permitted which does not comply with these terms. 